Abstract 252 Table 3 (1) Comparing SLE vs non-SLE using 'N-1' Chi-squared test; (2) Comparing black SLE patients to while SLE patients using 'N-1' chi-squared test

\begin{tabular}{|l|c|c|c|}
\hline & SLE = n (\%) & non SLE =n (\%) & p-value \\
\hline Overdue & $363(60.09 \%)$ & $1,709(51.21 \%)$ & $P=0.0022$ \\
\hline Not due & $241(39.90 \%)$ & $1,628(48.59 \%)$ & $P=0.0117$ \\
\hline Overdue with prior HPV positivity & $35(19.66 \%)$ & $150(20.74 \%$ & $P=0.8871$ \\
\hline Not due with prior HPV positivity & $60(28.70 \%)$ & $330(20.60 \%)$ & $P=0.1630$ \\
\hline Overdue in black population & $180(56.60 \%)$ & $688(46.36 \%)$ & $P=0.0144$ \\
\hline Overdue in white population & $138(43.39 \%)$ & $796(53.63 \%)$ & $P=0.0263$ \\
\hline $\begin{array}{l}\text { Overdue with prior HPV positivity in black } \\
\text { population }\end{array}$ & $21(70 \%)$ & $77(55.39 \%)$ & $P=0.2308$ \\
\hline $\begin{array}{l}\text { Overdue with prior HPV positivity in white } \\
\text { population }\end{array}$ & $9(30 \%)$ & $62(44.60 \%)$ & $P=0.4114$ \\
\hline $\begin{array}{l}\text { Not due with prior HPV positivity in black } \\
\text { population }\end{array}$ & $138(66.02 \%)$ & $168(59.94 \%)$ & $P=0.2746$ \\
\hline $\begin{array}{l}\text { Not due with prior HPV positivity in white } \\
\text { population }\end{array}$ & $71(33.97 \%)$ & $127(43.05 \%)$ & $P=0.2118$ \\
\hline
\end{tabular}

\begin{tabular}{|l|l|l|c|}
\hline \multicolumn{2}{|c|}{ Black } & \multicolumn{1}{c|}{ White } & P value \\
\hline Overdue & $180(56.60 \%)$ & $138(43.39 \%)$ & $\mathrm{P}=0.0197$ \\
\hline Overdue with prior HPV positivity & $21(70 \%)$ & $9(30 \%)$ & $\mathrm{P}=0.0455$ \\
\hline Not due with prior HPV positivity & $138(66.02 \%)$ & $71(33.97 \%)$ & $\mathrm{P}<0.0001$ \\
\hline
\end{tabular}

\section{VALIDATION AND RELIABILITY OF A DISEASE-SPECIFIC QUALITY OF LIFE MEASURE IN PATIENTS WITH CUTANEOUS LUPUS ERYTHEMATOSUS}

${ }^{1}$ Motolani E Ogunsanya, ${ }^{2}$ Stephanie K Cho, ${ }^{3}$ Andrew Hudson, ${ }^{2}$ Benjamin F Chong* ${ }^{1}$ College of Pharmacy, University of Oklahoma Health Sciences Center; ${ }^{2}$ Department of Dermatology, University of Texas Southwestern Medical Center; ${ }^{3}$ Texas Tech University Health Sciences Center

\subsection{6/lupus-2019-|sm.253}

Background Cutaneous lupus erythematosus (CLE) is a potentially disfiguring, chronic autoimmune disease with variable skin manifestations, negatively affecting the quality of life (QoL) of patients. Patient-reported outcome (PRO) measures used in assessing QoL in CLE patients have been either generic or developed without input from patients with CLE. The objective of this study was to demonstrate the reliability and validity of a disease-specific QoL measure for CLE the cutaneous lupus erythematosus quality of life (CLEQoL).

Methods A total of 101 patients with a diagnosis of CLE were recruited at outpatient dermatology clinics at the University of Texas Southwestern Medical Center and Parkland Health and Hospital System in Dallas, TX. Each patient was asked to complete the CLEQoL and Short Form 36 (SF-36). The CLEQoL contains 29 questions from the SKINDEX, a generic skin disease QoL measure, three questions relating to photosensitivity and alopecia (adapted from the SKINDEX$29+3)$, and four questions from the vitiligo-specific quality of life (VitiQoL) (figure 1). These questions were validated via focus groups of patients with CLE. Internal consistency was used as a measure of reliability. Validity was measured in two ways structural validity via exploratory factor analysis and convergent validity via Spearman correlations between CLEQoL and SF-36. Patient demographic and disease characteristics were collected. Data was analyzed using SPSS and significance was set to $\mathrm{p}<0.05$.

Results The average age of our CLE patients was $48 \pm 13$ with discoid lupus $(n=72,71.3 \%)$ being the most predominant CLE subtype. Patients were mostly female $(n=88$, $87.1 \%)$ and African-American/Black $(n=59,58.4 \%)$. Internal consistency ranged from 0.67 to 0.95 . A total of five domains, functioning, emotions, symptoms, body image/cosmetic effects and photosensitivity, were extracted with a total explained variance of $71.06 \%$. CLEQoL-related domains correlated with SF-36 domains ( $\mathrm{r}$ ranging from -0.39 to -0.65). The Cutaneous Lupus Activity and Severity Index (CLASI) activity scores correlated positively with the CLEQoL functioning $(\mathrm{r}=0.24, \mathrm{p}<0.05)$, emotions $(\mathrm{r}=0.26$, $\mathrm{p}<0.05)$, and symptoms $(\mathrm{r}=0.32, \mathrm{p}<0.05)$ domains. CLASI damage scores correlated positively with the CLEQoL body image/cosmetic effects $(r=0.41, p<0.001)$ and photosensitivity $(\mathrm{r}=0.25, \mathrm{p}<0.05)$.

Conclusions The CLEQoL was found to be a valid and reliable PRO measure for assessing QoL in patients with CLE. Demonstrating that the CLEQoL has strong psychometric properties is an important step towards the development of a disease-specific PRO measure for future CLE clinical trials.

Funding Source(s): This study was supported by the National Institute of Arthritis and Musculoskeletal and Skin Diseases under Award Number K23AR061441. 


\begin{tabular}{|c|c|c|c|c|c|}
\hline $\begin{array}{l}\text { These questions concern your feelings over the past } 4 \text { weeks about } \\
\text { the skin condition that has bothered you the most. Check the } \\
\text { answer that comes closest to the way you have been feeling. }\end{array}$ & NEVER & RARELY & SOMETIMES & OFTEN & $\begin{array}{l}\text { ALL THE } \\
\text { TIME }\end{array}$ \\
\hline 1. My skin hurts & $\square_{1}$ & $\square_{2}$ & $\square_{3}$ & $\square_{4}$ & $\square_{5}$ \\
\hline 2. My skin condition affects how well I sleep & $\square_{1}$ & $\square_{2}$ & $\square_{3}$ & $\square_{4}$ & $\square_{5}$ \\
\hline 3. I worry that my skin condition may be serious & $\square_{1}$ & $\square_{2}$ & $\square_{3}$ & $\square_{4}$ & $\square_{5}$ \\
\hline 4. My skin condition makes it hard to work or do hobbies & $\square_{1}$ & $\square_{2}$ & $\square_{3}$ & $\square_{4}$ & $\square_{5}$ \\
\hline 5. My skin condition affects my social life & $\square_{1}$ & $\square_{2}$ & $\square_{3}$ & $\square_{4}$ & $\square_{5}$ \\
\hline 6. My skin condition makes me feel depressed & $\square_{1}$ & $\square_{2}$ & $\square_{3}$ & $\square_{4}$ & $\square_{5}$ \\
\hline 7. My skin condition burns or stings & $\square_{1}$ & $\square_{2}$ & $\square_{3}$ & $\square_{4}$ & $\square_{5}$ \\
\hline 8. I tend to stay at home because of my skin condition & $\square_{1}$ & $\square_{2}$ & $\square_{3}$ & $\square_{4}$ & $\square_{5}$ \\
\hline 9. I worry about getting scars from my skin condition & $\square_{1}$ & $\square_{2}$ & $\square_{3}$ & $\square_{4}$ & $\square_{5}$ \\
\hline 10. My skin itches & $\square_{1}$ & $\square_{2}$ & $\square_{3}$ & $\square_{4}$ & $\square$ 唯 \\
\hline 11. My skin condition affects how close I can be with those I love & $\square_{1}$ & $\square_{2}$ & $\square_{3}$ & $\square_{4}$ & $\square_{5}$ \\
\hline 12. I am ashamed of my skin condition & $\square_{1}$ & $\square_{2}$ & $\square_{3}$ & $\square_{4}$ & $\square_{5}$ \\
\hline 13. I worry that my skin condition may get worse & $\square_{1}$ & $\square_{2}$ & $\square_{3}$ & $\square_{4}$ & $\square_{5}$ \\
\hline 14. I tend to do things by myself because of my skin condition & $\square_{1}$ & $\square_{2}$ & $\square_{3}$ & $\square_{4}$ & $\square_{5}$ \\
\hline 15. I am angry about my skin condition & $\square_{1}$ & $\square_{2}$ & $\square_{3}$ & $\square_{4}$ & $\square_{5}$ \\
\hline 16. Water bothers my skin condition (bathing, washing hands) & $\square_{1}$ & $\square_{2}$ & $\square_{3}$ & $\square_{4}$ & $\square_{5}$ \\
\hline 17. My skin condition makes showing affection difficult & $\square_{1}$ & $\square_{2}$ & $\square_{3}$ & $\square_{4}$ & $\square_{5}$ \\
\hline 18. I worry about side-effects from skin medications / treatments & $\square_{1}$ & $\square_{2}$ & $\square_{3}$ & $\square_{4}$ & $\square_{5}$ \\
\hline 19. My skin is irritated & $\square_{1}$ & $\square_{2}$ & $\square_{3}$ & $\square_{4}$ & $\square_{5}$ \\
\hline 20. My skin condition affects my interactions with others & $\square_{1}$ & $\square_{2}$ & $\square_{3}$ & $\square_{4}$ & $\square_{5}$ \\
\hline 21. I am embarrassed by my skin condition & $\square_{1}$ & $\square_{2}$ & $\square_{3}$ & $\square_{4}$ & $\square_{5}$ \\
\hline 22. My skin condition is a problem for the people I love & $\square_{1}$ & $\square_{2}$ & $\square_{3}$ & $\square_{4}$ & $\square 5$ \\
\hline 23. I am frustrated by my skin condition & $\mathbf{\square}_{1}$ & $\square_{2}$ & $\square_{3}$ & $\square_{4}$ & $\square_{5}$ \\
\hline 24. My skin is sensitive & $\square_{1}$ & $\square_{2}$ & $\square_{3}$ & $\square_{4}$ & $\square$ 唯 \\
\hline 25. My skin condition affects my desire to be with people & $\square_{1}$ & $\square_{2}$ & $\square_{3}$ & $\square_{4}$ & $\square_{5}$ \\
\hline 26. I am humiliated by my skin condition & $\square_{1}$ & $\square_{2}$ & $\square_{3}$ & $\square_{4}$ & $\square_{5}$ \\
\hline 27. My skin condition bleeds & $\square_{1}$ & $\square_{2}$ & $\square_{3}$ & $\square_{4}$ & $\square_{5}$ \\
\hline 28. I am annoyed by my skin condition & $\square_{1}$ & $\square_{2}$ & $\square_{3}$ & $\square_{4}$ & $\square 5$ \\
\hline 29. My skin condition interferes with my sex life & $\square_{1}$ & $\square_{2}$ & $\square_{3}$ & $\square_{4}$ & $\square_{5}$ \\
\hline 30. My skin condition makes me tired & $\square_{1}$ & $\square_{2}$ & $\square_{3}$ & $\square_{4}$ & $\square_{5}$ \\
\hline 31. I worry about going outside because the sun might flare my disease & $\square_{1}$ & $\square_{2}$ & $\square_{3}$ & $\square_{4}$ & $\square_{5}$ \\
\hline 32. I am worried about my hair loss & $\square_{1}$ & $\square_{2}$ & $\square_{3}$ & $\square_{4}$ & $\square_{5}$ \\
\hline 33. My skin disease prevents me from doing outdoor activities & $\square_{1}$ & $\square_{2}$ & $\square_{3}$ & $\square_{4}$ & $\square_{5}$ \\
\hline $\begin{array}{l}\text { 34. When talking to someone, I worry about what they may be thinking of } \\
\text { me }\end{array}$ & $\square_{1}$ & $\square_{2}$ & $\square_{3}$ & $\square_{4}$ & $\square_{5}$ \\
\hline 35. My skin condition influences the clothes I wear & $\square_{1}$ & $\square_{2}$ & $\square_{3}$ & $\square_{4}$ & $\square_{5}$ \\
\hline $\begin{array}{l}\text { 36. My skin condition affects my grooming practices (e.g., haircut, use of } \\
\text { cosmetics) }\end{array}$ & $\square_{1}$ & $\square_{2}$ & $\square_{3}$ & $\square_{4}$ & $\square_{5}$ \\
\hline $\begin{array}{l}\text { 37. My skin condition affects my sun protection habits during recreation } \\
\text { (e.g., limiting exposure time during sun peak hours, seeking shade, }\end{array}$ & $\square_{1}$ & $\square_{2}$ & $\square_{3}$ & $\square_{4}$ & $\square_{5}$ \\
\hline
\end{tabular}

wearing a hat, long sleeves or pants)

Abstract 253 Figure 1 The CLE-specific quality of life measure CLEQoL

\section{IDENTIFICATION OF DAMAGE CLUSTERS IN SYSTEMIC LUPUS ERYTHEMATOSUS}

${ }^{1} \mathrm{Ga}$ Young Ahn, ${ }^{2}$ Jiyoung Lee, ${ }^{2}$ Soyoung Won, ${ }^{3} \mathrm{E}$ unji Ha, ${ }^{1}$ Hyoungyoung Kim, ${ }^{1} \mathrm{Ji}$ Soong Kim, 'Juyeon Kang, 'Bora Nam, 'So-Young Bang, ${ }^{4}$ Seung Cheol Shim, 'HyeSoon Lee, ${ }^{5}$ Kwangwoo Kim, ${ }^{1}$ Sang-Cheol Bae*. ${ }^{1}$ Department of Rheumatology, Hanyang University Hospital for Rheumatic Diseases; ${ }^{2}$ Clinical Research Center for Rheumatioid Arthritis; ${ }^{3}$ Department of Biology, Kyung Hee University; ${ }^{4}$ Division of Rheumatology, Department of Internal medicine, Chungnam National University; ${ }^{5}$ Department of Biology, Kyung Hee University, Republic of Korea

10.1136/lupus-2019-Ism.254

Background Damage in SLE is an irreversible change of organ system results from SLE involvement or adverse effects of medications. Recently, the awareness and evidence of subphenotypes in SLE has been increased. In this study, thus we are to identify damage clusters and compare organ damage involvement, demographic and clinical manifestations, mortality and weighted genetic risk score (GRS) between clusters.

Methods The study was conducted from Hanyang Bae lupus Cohort. Patients whose disease duration is less than 5 years were excluded to minimize potential confounding effects of disease duration. Patients were grouped into 3 clusters based on SLICC Damage Index (SDI) at last follow-up visit using Kmean cluster analysis. Comparison of characteristics between clusters were performed using ANOVA and Chi-square test. Results A total number of 1130 patients were analyzed. Both the last follow-up visit, musculoskeletal damage was the most frequent damage domain followed by ocular, renal and 